\title{
Diseño De Un Plan De Manejo Ambiental Para La Planta De Producción De Materiales Pétreos, Hormigón Y Asfalto La Josefina, Cantón Gualaceo, Provincia Del Azuay
}

\author{
Norma Ximena Lara Vásconez \\ Oscar Bladimiro Guadalupe Arias \\ Juan Pablo Guamán \\ Eduardo Salazar \\ Escuela Superior Politécnica de Chimborazo - Ecuador
}

doi: 10.19044/esj.2017.v13n26p157 URL:http://dx.doi.org/10.19044/esj.2017.v13n26p157

\begin{abstract}
This research was to propose the elaborate of a Design Plan for Environmental Management Production Plant Stone Materials, Concrete and Asphalt in Josefina town, Gualaceo city, in Azuay province; it based on the collection of both primary and secondary, in addition to characteristics of the environment and population of area influence proceeded to design environmental management plan, these programs the same which is composed of nine programs intended to prevent or mitigate environmental impacts caused by the operation of the same, are: Communication Program, Community Relations, Training and Environmental Education, discharges and Waste Management, Safety and Occupational Health Laboring, contingencies, Prevention and Control of Impacts, Closure and Abandonment, Environmental Monitoring and Security. This research conclude that the most affected components are soil, water, flora and fauna and it is essential to fully comply all programs previously proposed in order to mitigate environmental impacts cauded by the operation of the Production Plant Stone Materials, Concrete and Asphalt. It is recommended to train staff, especially in first aid and use PPE (Personal Protective Equipment) so they will be prepared for any eventuality to occur during the operation of the plant.
\end{abstract}

Keywords: Environmental Management Plan, Design, Management, Program, Production Plant, Prevention 


\section{Resumen}

La presente investigación propone elaborar un Diseño de Plan de Manejo Ambiental para la Planta de Producción de Materiales Pétreos, Hormigón y Asfalto la Josefina, Cantón Gualaceo, Provincia del Azuay; en base a la recopilación de información tanto primaria como secundaria además de las características del medio ambiente y población del área de influencia se procedió a realizar el Diseño del Plan de Manejo Ambiental, el mismo que está compuesto de nueve programas que pretende prevenir y/o mitigar los impactos ambientales ocasionados por el funcionamiento de la misma, estos programas son: Programa de Comunicación, Programa de Relaciones Comunitarias, Programa de Capacitación y Educación Ambiental, Programa de Manejo de Desechos y Vertidos, Programa de Seguridad Laboral y Salud Ocupacional, Programa de Contingencias, Programa de Prevención y Control de Impactos, Programa de Cierre y Abandono, Programa de Monitoreo y Seguimiento Ambiental. Se concluye que los componentes más afectados son suelo, agua, flora y fauna por lo que se hace indispensable cumplir a cabalidad todos los programas propuestos anteriormente con el fin de mitigar los impactos ambientales ocasionados por el funcionamiento de la Planta de Producción de Materiales Pétreos, Hormigón y Asfalto. Se recomienda capacitar al personal, sobre todo en primeros auxilios y uso de EPP, de esta manera estarán preparados para cualquier eventualidad que ocurriera en el transcurso del funcionamiento de la Planta.

Palabras-claves: Plan de Manejo Ambiental, Diseño, Manejo, Programa, Planta de Producción, Prevención

\section{Introducción}

La producción de agregados pétreos así como hormigón y asfalto es de gran importancia a nivel mundial, las cuales son destinadas para obras de ingeniería, construcción, mejoramiento y mantenimiento de vías entre otras (Ramírez, 2008). Actualmente estas plantas de procesamiento se encuentran distribuidos ampliamente por todo el país, y a su vez esta es una de las principales fuentes de crecimiento económico por lo tanto de bienestar para la sociedad, es importante tener en cuenta que la eficiencia de la producción de estos materiales y su costo tiene impactos importantes sobre la economía local y regional (González, 2007).

Pero por los efectos ambientales provocados por la producción de dichos materiales, el manejo de desechos inadecuado, la ausencia de un plan de producción amigable con el ambiente puede generar rechazo, más aún 
cuando existen precedentes de efectos ambientales muy negativos afectando a la integridad de poblaciones cercanas a estos lugares (Páez, 1991)

En la mayor parte de la región se encuentran instaladas Plantas de procesamiento de agregados pétreos, las cuales están ubicadas juntos a centros de desarrollo urbano, por lo que resulta lógico que causen un gran impacto ambiental, sin embargo algunos de estos lugares carecen de un plan de manejo ambiental las cuales les permitan tener un adecuado manejo y administración de los recursos naturales (Estadística ARCOM, 2015).

En este contexto se realiza el Diseño de Plan de Manejo Ambiental como instrumento de gestión destinado a proveer una guía de programas, procedimientos, prácticas y acciones, orientados a prevenir, minimizar y controlar la intensidad de los impactos ambientales negativos generados sobre los componentes biofísico, socioeconómico y cultural, provocados por el funcionamiento de la planta de materiales pétreos, hormigón y asfalto (García, 2013).

Dicho Diseño de Plan De Manejo Ambiental se encuentra acorde a la Normativa Ambiental vigente entre las cuales se encuentra la Ley de Gestión Ambiental, el Texto Unificado de Legislación Ambiental Secundaria del Ministerio del Ambiente (TULAS) y de otros cuerpos jurídicos que pudiesen aplicarse en Ecuador (TULAS, 2013).

\section{Metodología}

Esta investigación se realizó en La Planta De Producción De Materiales Pétreos, Hormigón Y Asfalto La Josefina, Cantón Gualaceo, Provincia Del Azuay, ubicada a una altitud de 2320 m.s.n.m. con temperatura promedio anual de $17^{\circ} \mathrm{C}$, precipitación promedio anual de $1864.20 \mathrm{~mm}$, vientos que alcanzan velocidades de $0,3 \mathrm{~km} / \mathrm{h}$, el afluente más cercano es el rio Jadán, teniendo este sitio un clima Subtropical Subandino según (Cañadas, 1986).

La investigación se realizó utilizando el método Exploratorio, cualitativo y analítico durante la elaboración:

Se realizó la recopilación de información primaria y secundaria de las características del ambiente, población del área de influencia y operación, esto con el fin de realizar una evaluación del deterioro ambiental que causan las actividades de operación de la Planta de materiales pétreos, hormigón y asfalto.

Con el objetivo de identificar los principales impactos ambientales generados por la realizamos la Descripción del área de implantación y de las actividades en la planta de producción de materiales pétreos, hormigón y asfalto. 


\section{Descripción del área de implantación}

La planta de producción de materiales pétreos, hormigón y asfalto la josefina, es un área plana de forma irregular cuya superficie total es de 14,6 has, sin embargo la superficie realmente utilizada es de aproximadamente 8,0 has.

\section{Geología y Geomorfología}

La geología donde se encuentra ubicada la Planta está dentro de la Formación Yunguilla, la cual se presenta prácticamente en un cinturón que se extiende aproximadamente desde el Sur de Ingapirca, hasta cerca de Cumbe, está conformada por lutitas y argilitas de colores negros, que en su mayor parte se encuentran silicificadas y bien laminadas, sin embargo en el sector del Descanso y en el propio sector donde está ubicada la Planta, se puede distinguir un metamorfismo de bajo grado y donde las rocas han tomado un color amarillento, las cuales se encuentran fracturadas con clastos angulosos y conformando capas.

El sitio es una morfología irregular, flanqueado por dos formaciones montañosas que corren de Sur a Norte con ligeras variaciones en lo que a rumbos se refiere, presentan un relieve abrupto en sus laderas con fuertes pendientes con escarpes en su lado Este y Sur-Este. El lado Oeste y NorOeste, tiene un relieve más suave y sus pendientes, pese a ser fuertes, no se asemejan a las de su par del Este. Las cimas de las mismas presentan formas redondeadas y ligeramente alargadas.

\section{Pendiente}

La pendiente en este sector está formada por colinas de perfiles suaves, presencia de barrancos y denudación activa, que ha dejado al descubierto las estructuras geológicas, mostrando perfiles en escalera en las rocas horizontales y asimétricas en los planos inclinados. Se puede observar en el flanco Oriental del sector, un deslizamiento muy antiguo y de grandes proporciones, el cual modificó el sistema de drenaje natural del sector. El drenaje en el lugar se encuentra constituido por el rio Jadán, que cruza el área de implantación de la Planta de Sur-Oeste a Nor-Este, la misma que presenta anchos de cauce variables, formando valles tipo "V", típicos de la serranía ecuatoriana.

\section{Suelo}

Los suelos son residuales, de color negro, de texturas finas (areno arcillosas a arcillosas), con fragmentos gruesos (gravillas y gravas), muy poco alterados, con presencia de grietas, en muchos de los casos con potencias muy delgadas e inclusive en sectores con pendientes fuertes, son superficiales, los cuales son producto de la descomposición de las rocas 
preexistentes (sedimentarias), los cuales se han ubicado en las partes bajas ya que como se menciona anteriormente prácticamente todo el sector está conformado por pendientes abruptas y colinas redondeadas, mismas que no favorecen la formación de suelos.

Aire

El aire en el sector son aceptables ya que en el lugar existe recirculación debido al valle que forma el rio Jadán, el cual sirve como un túnel de viento el mismo que refresca, modifica y mejora la renovación. El sector no presenta ruidos fuertes en forma natural, la poca población existente en los alrededores del sector, emite ruidos esporádicos producto de sus actividades diarias.

\section{Flora y Fauna}

La flora está constituida por por Molle (Schinus molle L), Acacia (Acacia megaloxylon), Eucalipto (Eucalyptus globulus), Penco (Agave americana), Kikuyo (Pennisetum clandestinum), Chilca (Baccharis floribunda), Retama (Spartium junceum), Altamiso (Ambrosia arborescens), Sigse (Cortaderia nitida), Cenizo (Chenopodium paniculatum), Guasca (Galinsoga ciliata), entre otros.

La fauna local ha sido casi exterminada, pero se puede encontrar algunas especies como Gallinazos de Cabeza Negra (Coragyps atratus), Gorrión (Zonotricha capensis), Golondrina (Notiochelidon murina), Cuturpilla (Columbina passerina). De acuerdo al recorrido realizado en el lugar, no se pudo encontrar ningúna especie en particular, según los relatos de los moradores de la Planta aún existen mamíferos tales como: Ratón de Campo (Oryzomys leucodactylus), Zorrillo (Connenatus chinga), Raposa (Calorumiys lanatus), Conejo (Sylvilagus brasilienses), y Reptiles tales como la Lagartija (Anolis nigrolineatus) y el Sapo Común.

\section{Descripción de los principales servicios (Salud, Alimentación, Educación)}

En el lugar prácticamente no cuenta con los servicios básicos es decir sistema de alcantarillado, ni doméstico, ni pluvial, utilizando la mayor parte de las viviendas el sistema de fosas sépticas, al estar las casas dispersas muy pocas cuentan con energía eléctrica. Los infantes y adolescentes se educan principalmente en los sectores del Cabo, Paute, Cuenca y Azogues. En lo que se refiere a la salud, la población generalmente acude a la ciudad de Cuenca para acceder a atención médica. 


\section{Demografía, Actividades Socio-Económicas, Aspectos Culturales, Migración}

En el sector en si no existen poblados grandes o barrios que pudiesen verse afectados por la presencia de las instalaciones de la Planta, pues existen solamente casas dispersas, y considerablemente alejadas del área de la Planta. La poca población existente en el lugar se ejercen la agricultura y el resto de población a la ganadería, mientras que en un porcentaje bastante alto se dedica a actividades tales como obreros para la construcción, peones y labores varias.

Los pocos habitantes del sector, manifiestan que cuentan con tradiciones populares inculcadas desde sus ancestros y practican en su mayor porcentaje la religión católica. La migración es un fenómeno característico del sector y prácticamente de toda la región austral del Ecuador, siendo los principales destinos para la migración los Estados Unidos y Europa.

\section{Descripción de las actividades en la planta de producción de materiales pétreos, hormigón y asfalto. \\ Campamento}

Cuenta con la suficiente infraestructura para albergar al personal que labora en la Planta, esta adecuado con la ayuda de contenedores metálicos, mismo que se ubica al Sur de la superficie que ocupa la Planta y a una distancia segura para evitar cualquier afectación hacia el personal. Este campamento es totalmente desmontable y al finalizar todas las actividades que se dan en el lugar este será trasladado hacia otro sitio.

\section{Oficina, bodega, área de mantenimiento}

En el caso de la Oficina Técnica y Bodega, estos tienen el carácter de temporales y están ubicadas en contenedores metálicos, por lo cual son móviles y de muy fácil transportación, mismos que están montados sobre pilotes por encima de la superficie del suelo.

En el caso del Área de Mantenimiento, se ubica sobre una superficie encementada con cubierta de estructura metálica.

\section{Área de almacenamiento de combustibles}

Ya que es necesario mantener suficiente combustibles disponibles para el funcionamiento de la maquinaria y demás equipos, se ha destinado un área específica para su almacenamiento la misma que se encuentra bajo las normas técnicas para su debida utilización la cual se encuentra debidamente señalizada. 


\section{Maquinaria y equipos}

Para la operación de la Planta de Materiales Pétreos, se cuenta con los siguientes equipos:

Planta de Asfalto, Planta de Hormigón, Generadores Eléctricos, Volquetas, Trituradoras, Cargadoras, Herramientas y equipo menor

\section{Etapas del Proceso Productivo}

Stock y apilamiento del material

Todos los materiales procedentes de las áreas de explotación son acumulados cerca de la Planta, para de esta forma reducir el tiempo de las labores de carga y descarga, estos materiales posteriormente pasarán a la etapa de Trituración.

\section{Clasificación}

Se realiza la clasificación de los materiales esto con la finalidad de mejorar el proceso productivo, la clasificación de los materiales extraídos de las áreas de explotación se lo realiza vía seca, por medio de una criba fija montada a desnivel, en donde la volqueta descarga las rocas y por diferencia de diámetro se clasifica el material pétreo para posteriormente ser llevado al área de trituración.

\section{Trituración del material}

El material pétreo el cual se encuentra apilado, se lo transporta hacia el lugar de Trituración para la obtención de materiales con medidas de 1 1 2 , $3 / 4$ y $3 / 8$ de pulgada (ripio, polvo de piedra y piedra chispa), los cuales luego son transportados a la planta asfáltica o de hormigón según su necesidad.

\section{Elaboración de asfalto}

El material con medidas de $3 / 4$ y $3 / 8$ de pulgada más arena, son enviados hacia la planta de asfalto, en donde se cargan las tolvas con la ayuda de una cargadora frontal, ahí será dosificado y mezclado con asfalto líquido para la obtención de la mezcla asfáltica, conforme a las especificaciones técnicas para su utilización.

\section{Elaboración de hormigón}

La preparación de hormigón se lo realiza con la utilización de materiales triturados los cuales son llevados hacia una tolva y silos en donde se adiciona cemento a granel y se dosifica los materiales pétreos para obtener hormigón, el cual será utilizado en la vía, ya sea para la construcción de puentes, obras complementarias, entre otros. 


\section{Transporte}

El transporte de asfalto se lo realiza con la ayuda de volquetes, los mismos que se movilizan hacia los frentes de trabajo para descargar el asfalto en la maquina denominada Finisher. Mientras que el Hormigón se lo realiza en vehículos especiales denominados Mixers, los cuales llevan su contenido manteniéndolo en forma de pasta para de esta forma evitar su fraguado hasta llegar a la obra donde sea necesario.

Obtenidos estos datos se procedimos a Plantear un plan de manejo a través de programas que ayuden a la prevención, mitigación, compensación y control de los impactos ambientales producto de la operación de la planta de materiales pétreos, hormigón y asfalto la Josefina, Cantón Gualaceo, Provincia del Azuay.

\section{Programas de Diseño del Plan de Manejo Ambiental}

Programa de Comunicación, Programa de Relaciones Comunitarias, Programa de Capacitación y Educación Ambiental, Programa de Manejo de Desechos y Vertidos, Programa de Seguridad Laboral y Salud Ocupacional, Programa de Contingencias, Programa de Prevención y Control de Impactos, Programa de Cierre y Abandono, Programa de Monitoreo y Seguimiento Ambiental. Los programas del diseño de Plan de Manejo, se encuentran constituidos en formatos de fichas individuales, las cuales constan de la siguiente información: Nombre de la Medida, Objetivo de la Medida, Etapa de Ejecución (Operación, Mantenimiento, Cierre y Abandono), Tipo de Medida (Prevención, Compensación, Mitigación), Plazo para la Implementación, Actividades a Desarrollar, Impacto a Controlar, Costo de la Medida, Indicador de Cumplimiento, Medios de Cumplimiento

\section{Resultados}

Cuadro1. Principales impactos ambientales

\begin{tabular}{|c|c|c|c|}
\hline \multicolumn{4}{|c|}{ PRINCIPALES IMIPACTOS AMIBIENTALES } \\
\hline $\begin{array}{c}\text { Aspecto } \\
\text { Ambiental }\end{array}$ & Impacto Ambiental & $\begin{array}{l}\text { Positivo / } \\
\text { Negativo }\end{array}$ & Etapa \\
\hline \multirow{3}{*}{ Suelo } & Compactación de los suelos naturales. & Negativo & Operación \\
\hline & $\begin{array}{c}\text { Generación de desechos orgánicos e } \\
\text { inorgánicos. }\end{array}$ & Negativo & Operación \\
\hline & Erosión & Negativo & Operación \\
\hline \multirow[b]{3}{*}{ Aire } & $\begin{array}{l}\text { Incremento de material particulado (Polvo } \\
\text { en el ambiente). }\end{array}$ & Negativo & Operación \\
\hline & Incremento de los niveles de ruido & Negativo & Operación \\
\hline & $\begin{array}{l}\text { Generación de Gases, producto de la } \\
\text { combustión interna de combustibles de } \\
\text { motores de la maquinaria y equipo } \\
\text { utilizado (Planta de Asfalto). }\end{array}$ & Negativo & Operación \\
\hline Agua & Generación de aguas de proceso & Negativo & Operación \\
\hline
\end{tabular}




\begin{tabular}{|c|c|c|c|}
\hline & (Planta de Asfalto). & & \\
\hline Flora & Revegetación de las áreas afectadas. & Positivo & Cierre \\
\hline Paisaje & $\begin{array}{l}\text { Cambios en la estructura paisajística de la } \\
\text { zona. }\end{array}$ & Negativo & Operación \\
\hline $\begin{array}{c}\text { Socio- } \\
\text { Culturales } \\
\end{array}$ & $\begin{array}{l}\text { Generación de expectativas por parte de los } \\
\text { moradores de la Planta. }\end{array}$ & Positivo & Operación \\
\hline \multirow{2}{*}{$\begin{array}{l}\text { Trafico y } \\
\text { Vialidad }\end{array}$} & $\begin{array}{l}\text { Congestión vehicular en horas pico } \\
\text { generado por el transporte de hormigón, } \\
\text { asfalto por parte los volquetes. }\end{array}$ & Negativo & Operación \\
\hline & $\begin{array}{l}\text { Incremento del tráfico vehicular generado } \\
\text { por el transporte de hormigón, asfalto por } \\
\text { parte los volquetes. }\end{array}$ & Negativo & Operación \\
\hline \multirow[b]{2}{*}{ Seguridad } & $\begin{array}{l}\text { Riesgo para la integridad personal de } \\
\text { quienes transitan y laboran en la Planta. }\end{array}$ & Negativo & Operación \\
\hline & $\begin{array}{l}\text { Adopción de medidas de seguridad para } \\
\text { mejorar el tránsito (incremento de } \\
\text { señalización). }\end{array}$ & Positivo & Operación \\
\hline Empleo & Generación de puestos de trabajo. & Positivo & Operación \\
\hline
\end{tabular}


Cuadro 2. Programas que ayuden a la prevención, mitigación, compensación y control de los impactos ambientales producto de la operación de la planta de materiales pétreos, hormigón y asfalto la Josefina, Cantón Gualaceo, Provincia del Azuay.

\begin{tabular}{|c|c|c|c|c|c|c|c|}
\hline $\begin{array}{l}\text { NOMBRE DE } \\
\text { LA MEDIDA }\end{array}$ & $\begin{array}{l}\text { OBJETIVO DE } \\
\text { LA MEDIDA }\end{array}$ & $\begin{array}{l}\text { TIPO DE MEDIDA- } \\
\text { ETAPA DE EJECUCIÓN }\end{array}$ & $\begin{array}{l}\text { ACTIVIDADES A } \\
\text { DESARROLLAR }\end{array}$ & $\begin{array}{l}\text { PLAZO PARA } \\
\text { LA } \\
\text { IMPLEMENT } \\
\text { ACIÓN }\end{array}$ & $\begin{array}{l}\text { INDICADOR DE } \\
\text { CUMPLIMIENTO }\end{array}$ & $\begin{array}{c}\text { MEDIO DE } \\
\text { VERIFICACIÓN }\end{array}$ & COSTO \\
\hline \multicolumn{8}{|c|}{ PROGRAMA DE COMUNICACIÓN } \\
\hline $\begin{array}{l}\text { Información de } \\
\text { las Actividades } \\
\text { que se } \\
\text { realizan en la } \\
\text { Planta, dirigida a } \\
\text { los Habitantes } \\
\text { del Área de } \\
\text { Influencia }\end{array}$ & $\begin{array}{l}\text { Disminuir las } \\
\text { molestias a los } \\
\text { vecinos } \\
\text { causadas por } \\
\text { la Operación de } \\
\text { la Planta } \\
\text { mediante la } \\
\text { información a } \\
\text { los habitantes } \\
\text { del área de } \\
\text { influencia. }\end{array}$ & $\begin{array}{c}\text { Prevención - Pre } \\
\text { operación / operación }\end{array}$ & $\begin{array}{l}\text { Charlas informativas a los vecinos } \\
\text { del área de influencia de la misma, } \\
\text { dando a conocer el cronograma de } \\
\text { los trabajos a realizarse y de las } \\
\text { medidas ambientales que se } \\
\text { tomarán para prevenir, minimizar y } \\
\text { mitigar los impactos ambientales } \\
\text { ocasionados por el funcionamiento } \\
\text { de la Planta. }\end{array}$ & $\begin{array}{c}\text { Durante todo } \\
\text { el proceso de } \\
\text { funcionamient } \\
\text { o de la Planta o } \\
\text { cuando sea } \\
\text { necesario. }\end{array}$ & $\begin{array}{l}\text { Conocimiento de } \\
\text { las actividades a } \\
\text { realizarse en la } \\
\text { Planta por parte de } \\
\text { los habitantes del } \\
\text { área de influencia } \\
\text { de la Planta. }\end{array}$ & $\begin{array}{c}\text { Entrevistas a } \\
\text { moradores del } \\
\text { área de } \\
\text { influencia } \\
\text { Registro de } \\
\text { asistencia a } \\
\text { charlas de } \\
\text { información } \\
\text { Registro } \\
\text { Fotográfico de } \\
\text { charlas } \\
\text { informativas }\end{array}$ & $1.200,00$ \\
\hline \multicolumn{8}{|c|}{ PROGRAMA DE RELACIONES COMUNITARIAS } \\
\hline
\end{tabular}




\begin{tabular}{|c|c|c|c|c|c|c|c|}
\hline $\begin{array}{c}\text { Capacitación al } \\
\text { Personal }\end{array}$ & $\begin{array}{c}\text { Capacitar a } \\
\text { todo el personal } \\
\text { que labora en la } \\
\text { Planta para que } \\
\text { realicen los } \\
\text { trabajos con } \\
\text { respeto al } \\
\text { medio ambiente } \\
\text { y a los } \\
\text { pobladores que } \\
\text { habitan cerca } \\
\text { de la Planta. } \\
\text { Evitar molestias } \\
\text { a la población } \\
\text { vecina de la } \\
\text { Planta. }\end{array}$ & Prevención - Operación & $\begin{array}{l}\text { Se deberá mantener limpio el lugar } \\
\text { es decir no botar basura, restos de } \\
\text { comida, desperdicios, u otra } \\
\text { actividad que pudiese causar algún } \\
\text { tipo de molestias a los vecinos de la } \\
\text { Planta. Las volquetas que circulen } \\
\text { dentro y fuera del área de la Planta, } \\
\text { deberán hacerlo cumpliendo con los } \\
\text { límites de velocidad establecidos en } \\
\text { la Ley de Tránsito. Los conductores } \\
\text { de volquetes deberán guardar en su } \\
\text { manejo un comportamiento que } \\
\text { refleje respeto hacia otros } \\
\text { conductores, trabajadores, } \\
\text { moradores y transeúntes. Se deberá } \\
\text { evitar cualquier tipo de } \\
\text { inconveniente por parte del } \\
\text { personal que labora en la Planta } \\
\text { hacia los vecinos del lugar. El } \\
\text { personal que labora en la Planta no } \\
\text { deberá cambiarse la ropa de trabajo } \\
\text { en sitios abiertos y visibles desde el } \\
\text { exterior de la Planta. Todas las } \\
\text { instalaciones de la Planta deberán } \\
\text { cumplir con todas las normas de } \\
\text { seguridad establecidas. }\end{array}$ & $\begin{array}{c}\text { Durante las } \\
\text { fases de } \\
\text { Operación, } \\
\text { Mantenimiento } \\
\text { y Cierre de la } \\
\text { Planta. }\end{array}$ & $\begin{array}{c}\text { El personal que } \\
\text { labora en la Planta, } \\
\text { se encuentran } \\
\text { capacitados sobre } \\
\text { buenas prácticas } \\
\text { de convivencia } \\
\text { con los moradores } \\
\text { del sector. }\end{array}$ & $\begin{array}{c}\text { Constatación } \\
\text { directa de } \\
\text { letreros } \\
\text { indicando } \\
\text { normas de buen } \\
\text { comportamiento. } \\
\text { Registro } \\
\text { fotográfico de las } \\
\text { charlas de } \\
\text { capacitación. } \\
\text { Registro de } \\
\text { asistencia a las } \\
\text { charlas por parte } \\
\text { del personal. } \\
\text { Entrevistas a } \\
\text { personal de la } \\
\text { Planta. }\end{array}$ & $1.560,00$ \\
\hline
\end{tabular}




\begin{tabular}{|c|c|c|c|c|c|c|c|}
\hline $\begin{array}{c}\text { Capacitación y } \\
\text { Educación } \\
\text { Ambiental }\end{array}$ & $\begin{array}{c}\text { Capacitar al } \\
\text { todo el personal } \\
\text { que labora en la } \\
\text { Planta para que } \\
\text { todas las } \\
\text { actividades a } \\
\text { desarrollarse se } \\
\text { realicen con } \\
\text { respeto al } \\
\text { medio ambiente }\end{array}$ & Prevención - operación & $\begin{array}{l}\text { La intención de esta medida es que } \\
\text { todo el personal que labora en la } \\
\text { Planta se encuentre debidamente } \\
\text { capacitado para así evitar cualquier } \\
\text { tipo de inconveniente que se pueda } \\
\text { suscitar y que afecte al entorno } \\
\text { natural sino a la integridad física de } \\
\text { los trabajadores, para ello se tiene } \\
\text { planificado establecer programas de } \\
\text { capacitaciones, en el cual se deberá } \\
\text { impartir charlas en los siguientes } \\
\text { temas: Uso y Manejo correcto de } \\
\text { Extintores. Uso del Equipo de } \\
\text { Protección Personal (EPP). } \\
\text { Primeros Auxilios, Salud } \\
\text { Ocupacional e Higiene. Educación } \\
\text { Ambiental. Manejo de Desechos. }\end{array}$ & $\begin{array}{l}\text { Dos veces al } \\
\text { año }\end{array}$ & $\begin{array}{l}\text { Todo el personal } \\
\text { que labora en la } \\
\text { Planta, se } \\
\text { encuentra } \\
\text { debidamente } \\
\text { capacitado para } \\
\text { evitar cualquier } \\
\text { accidente y su } \\
\text { respuesta } \\
\text { inmediata también } \\
\text { para realizar un } \\
\text { buen manejo } \\
\text { ambiental de su } \\
\text { actividad. }\end{array}$ & $\begin{array}{c}\text { Registros de } \\
\text { asistencia a } \\
\text { capacitaciones. } \\
\text { Registro } \\
\text { fotográfico de las } \\
\text { capacitaciones } \\
\text { Presentaciones } \\
\text { en PowerPoint. }\end{array}$ & $2.000,00$ \\
\hline \multicolumn{8}{|c|}{ PROGRAMA DE MANEJO DE DESECHOS Y VERTIDOS } \\
\hline $\begin{array}{c}\text { Gestión de } \\
\text { Desechos } \\
\text { Sólidos en la } \\
\text { Planta }\end{array}$ & $\begin{array}{c}\text { Controlar la } \\
\text { contaminación } \\
\text { ambiental por } \\
\text { la disposición } \\
\text { inadecuada de } \\
\text { desechos. } \\
\text { Cumplir con las } \\
\text { leyes y } \\
\text { regulaciones } \\
\text { ambientales } \\
\text { vigentes. } \\
\text { Identificar, } \\
\text { clasificar y } \\
\text { disponer los } \\
\text { desechos de } \\
\text { manera } \\
\text { adecuada } \\
\text { mediante la } \\
\text { utilización de } \\
\text { métodos }\end{array}$ & $\begin{array}{c}\text { Prevención / Mitigación - } \\
\text { Operación }\end{array}$ & Manejo de Desechos & $\begin{array}{c}\text { Inmediato y } \\
\text { durante las } \\
\text { Fases de } \\
\text { Operación y } \\
\text { Cierre }\end{array}$ & $\begin{array}{l}\text { Por parte del } \\
\text { personal de la } \\
\text { Planta se realiza } \\
\text { un manejo } \\
\text { adecuado de los } \\
\text { desechos } \\
\text { generados. }\end{array}$ & $\begin{array}{c}\text { Archivo } \\
\text { fotográfico } \\
\text { Constatación } \\
\text { directa } \\
\text { Registro envío de } \\
\text { Desechos a } \\
\text { Relleno } \\
\text { Sanitario. }\end{array}$ & 300,00 \\
\hline
\end{tabular}




\begin{tabular}{|c|c|c|c|c|c|c|c|}
\hline & $\begin{array}{c}\text { alternativos } \\
\text { aplicables a la } \\
\text { operación de la } \\
\text { Planta, los } \\
\text { cuales a medida }\end{array}$ & & & & & & \\
\hline $\begin{array}{c}\text { Manejo de } \\
\text { Desechos } \\
\text { Líquidos }\end{array}$ & $\begin{array}{c}\text { Prevenir y } \\
\text { minimizar los } \\
\text { impactos } \\
\text { generados por } \\
\text { los desechos } \\
\text { líquidos, sobre } \\
\text { los diferentes } \\
\text { componentes } \\
\text { ambientales en } \\
\text { el área de la } \\
\text { Planta. }\end{array}$ & $\begin{array}{c}\text { Prevención / Mitigación - } \\
\text { Operación }\end{array}$ & $\begin{array}{c}\text { Para el manejo de los Desechos } \\
\text { Líquidos, se deberá contar con } \\
\text { sistemas apropiados para el } \\
\text { tratamiento de aguas negras y } \\
\text { grises, que permitan el } \\
\text { cumplimiento con la Legislación } \\
\text { Ambiental (TULAS) o similares a } \\
\text { este. } \\
\text { Las aguas grises grasosas y } \\
\text { jabonosas serán conducidas por una } \\
\text { tubería a una trampa de grasas y } \\
\text { aceites para que por medio de } \\
\text { procesos físicos de sedimentación, } \\
\text { flotación y retención, se logre la } \\
\text { separación del material sólido. La } \\
\text { trampa de grasas y aceites es una } \\
\text { unidad conformada por un captador } \\
\text { y un sedimentador. } \\
\text { Los productos finales que se } \\
\text { obtienen después de la separación } \\
\text { son sólidos. Estos productos } \\
\text { deberán ser retirados de manera } \\
\text { trimestral, utilizando una pala y } \\
\text { depositados conjuntamente con los } \\
\text { desechos comunes. Las aguas } \\
\text { negras deberán ser tratadas por } \\
\text { medio de una fosa séptica. } \\
\text { Toda el agua utilizada para el } \\
\text { lavado/limpieza de equipos e }\end{array}$ & $\begin{array}{l}\text { Al inicio de los } \\
\text { trabajos en la } \\
\text { Planta }\end{array}$ & $\begin{array}{c}\text { Se realiza un buen } \\
\text { tratamiento de las } \\
\text { aguas negras y } \\
\text { grises generadas } \\
\text { en el campamento. }\end{array}$ & $\begin{array}{c}\text { Registros } \\
\text { fotográficos } \\
\text { Constatación } \\
\text { directa de } \\
\text { infraestructura. }\end{array}$ & $1.300,00$ \\
\hline
\end{tabular}




\begin{tabular}{|c|c|c|c|c|c|c|c|}
\hline & & & $\begin{array}{c}\text { instalaciones y otras, aguas } \\
\text { derivadas de los trabajos, deberá } \\
\text { controlarse y manejarse de tal } \\
\text { manera que no contamine el suelo o } \\
\text { cuerpos de agua. }\end{array}$ & & & & \\
\hline $\begin{array}{l}\text { Manejo de } \\
\text { Desechos } \\
\text { Peligrosos } \\
\text { (Aceites, Filtros } \\
\text { y Baterías } \\
\text { Usadas) }\end{array}$ & $\begin{array}{c}\text { Prevenir y } \\
\text { minimizar } \\
\text { riesgos e } \\
\text { impactos sobre } \\
\text { los diferentes } \\
\text { componentes } \\
\text { ambientales en } \\
\text { el área de la } \\
\text { Planta. }\end{array}$ & $\begin{array}{c}\text { Prevención / Mitigación - } \\
\text { Operación }\end{array}$ & $\begin{array}{l}\text { Manejo de Residuos Peligrosos. } \\
\text { Dentro de esta categoría se incluye } \\
\text { todos los productos residuales tales } \\
\text { como: aceites, filtros de aceite y } \\
\text { baterías todas estas ya usadas. Los } \\
\text { aceites y filtros, así como el } \\
\text { material contaminado con } \\
\text { hidrocarburos, serán entregados a } \\
\text { los gestores calificados por el } \\
\text { MAE. Por otro lado los envases que } \\
\text { almacenen cualquier tipo de } \\
\text { sustancia considerada como } \\
\text { Desecho Peligroso, debe estar } \\
\text { claramente ETIQUETADO de } \\
\text { acuerdo a los desechos que } \\
\text { contiene. Los envases deben estar } \\
\text { bajo techo y el piso debe estar } \\
\text { impermeabilizado. De preferencia } \\
\text { los envases deben ser recipientes de } \\
\text { 55 galones y se los almacenará en la } \\
\text { Bodega Desechos Peligrosos. }\end{array}$ & $\begin{array}{l}\text { Tres meses de } \\
\text { iniciada las } \\
\text { actividades en } \\
\text { la Planta }\end{array}$ & $\begin{array}{c}\text { Se realiza un buen } \\
\text { tratamiento de los } \\
\text { Desechos } \\
\text { Peligrosos, } \\
\text { conforme a lo } \\
\text { previsto en la } \\
\text { normativa } \\
\text { ambiental } \\
\text { establecida para el } \\
\text { efecto. }\end{array}$ & $\begin{array}{c}\text { Registros } \\
\text { fotográficos } \\
\text { Recipientes } \\
\text { adquiridos } \\
\text { Constatación } \\
\text { directa de } \\
\text { infraestructura } \\
\text { Registro de la } \\
\text { entrega de } \\
\text { Desechos a un } \\
\text { Gestor } \\
\text { Ambiental. }\end{array}$ & $2.375,00$ \\
\hline
\end{tabular}




\begin{tabular}{|c|c|c|c|c|c|c|c|}
\hline $\begin{array}{c}\text { Plan de } \\
\text { Seguridad } \\
\text { Laboral y Salud } \\
\text { Ocupacional }\end{array}$ & $\begin{array}{l}\text { Implementar } \\
\text { medidas para } \\
\text { garantizar la } \\
\text { seguridad y } \\
\text { salud de los } \\
\text { trabajadores } \\
\text { que laboran en } \\
\text { la Planta. } \\
\text { Prevenir y } \\
\text { minimizar los } \\
\text { riesgos de } \\
\text { accidentes } \\
\text { laborales } \\
\text { generando } \\
\text { ambientes } \\
\text { seguros de } \\
\text { trabajo y el uso } \\
\text { de Equipo de } \\
\text { Protección } \\
\text { Personal (EPP) }\end{array}$ & $\begin{array}{l}\text { Prevención - Operación/ } \\
\text { Mantenimiento/Cierre }\end{array}$ & $\begin{array}{l}\text { Capacitaciones al personal que } \\
\text { labora en la Planta por parte de un } \\
\text { Médico y técnico en el Área de } \\
\text { Seguridad Industrial, estos darán } \\
\text { charlas de salud y seguridad, } \\
\text { además de la importancia y } \\
\text { concientización del uso correcto del } \\
\text { EPP. } \\
\text { Se dotara a todo el personal que } \\
\text { labora en la Planta de EPP (ropa de } \\
\text { trabajo, chaleco retroreflectivo, } \\
\text { casco, guantes, zapatos de } \\
\text { seguridad, botas de caucho, } \\
\text { mascarillas, gafas protectoras de } \\
\text { ojos, protectores auditivos). }\end{array}$ & $\begin{array}{c}\text { Al iniciar las } \\
\text { labores en la } \\
\text { Planta }\end{array}$ & $\begin{array}{c}\text { Personal } \\
\text { correctamente } \\
\text { capacitado por } \\
\text { medio de charlas. } \\
\text { Dotación de EPP y } \\
\text { utilización por } \\
\text { parte de los } \\
\text { trabajadores. }\end{array}$ & $\begin{array}{l}\text { Constatación } \\
\text { directa del uso de } \\
\text { EPP por parte de } \\
\text { los trabajadores. } \\
\text { Registro de } \\
\text { dotación de EPP } \\
\text { hacia los } \\
\text { trabajadores. } \\
\text { Registro } \\
\text { fotográfico de las } \\
\text { charlas de } \\
\text { capacitación. } \\
\text { Registro de } \\
\text { asistencia a las } \\
\text { charlas por parte } \\
\text { del personal. }\end{array}$ & $\begin{array}{c}17.726,0 \\
0\end{array}$ \\
\hline $\begin{array}{c}\text { Señalización } \\
\text { Preventiva y } \\
\text { Delimitación del } \\
\text { Área }\end{array}$ & $\begin{array}{l}\text { Delimitar las } \\
\text { áreas de trabajo } \\
\text { de la Planta } \\
\text { para así } \\
\text { prevenir } \\
\text { accidentes que } \\
\text { se puedan } \\
\text { suscitar. } \\
\text { Restringir el } \\
\text { acceso de } \\
\text { personas no } \\
\text { autorizadas al } \\
\text { área de la } \\
\text { Planta. } \\
\end{array}$ & $\begin{array}{c}\text { Prevención - } \\
\text { Operación/Mantenimiento } \\
\text { / Cierre y Abandono }\end{array}$ & $\begin{array}{c}\text { Rotulación de áreas de trabajo } \\
\text { (cribas, trituradoras, Planta de } \\
\text { Hormigón, Planta de Asfalto, } \\
\text { Generadores, Trituradoras y Criba). } \\
\text { Rotulación de Dormitorios, } \\
\text { Comedor, Oficinas y Bodega. } \\
\text { Rotulación en área de } \\
\text { Mantenimiento. Rotulación de } \\
\text { precaución y peligro en todas las } \\
\text { áreas. Rotulación área de } \\
\text { almacenamiento de combustibles e } \\
\text { hidrocarburos (asfalto). Rotulación } \\
\text { con salidas de emergencia y puntos } \\
\text { de encuentro. }\end{array}$ & $\begin{array}{l}\text { Durante la } \\
\text { etapa de } \\
\text { operación, } \\
\text { mantenimiento } \\
\text { y cierre }\end{array}$ & $\begin{array}{l}\text { Toda el área de la } \\
\text { Planta, así como } \\
\text { su acceso, se } \\
\text { encuentran } \\
\text { debidamente } \\
\text { señalizados. }\end{array}$ & $\begin{array}{c}\text { Registro } \\
\text { fotográfico de la } \\
\text { señalización y } \\
\text { rotulación. } \\
\text { Constatación } \\
\text { directa } \\
\text { Facturas de } \\
\text { compra de } \\
\text { señalización }\end{array}$ & $2.644,00$ \\
\hline
\end{tabular}




\begin{tabular}{|c|c|c|c|c|c|c|c|}
\hline $\begin{array}{c}\text { Plan de } \\
\text { Contingencias } \\
\text { durante las } \\
\text { Operaciones de } \\
\text { la Planta }\end{array}$ & $\begin{array}{c}\text { Brindar } \\
\text { seguridad a los } \\
\text { trabajadores } \\
\text { mediante el } \\
\text { mantenimiento } \\
\text { de un área de } \\
\text { trabajo segura, } \\
\text { en donde esté } \\
\text { debidamente } \\
\text { planificado } \\
\text { acciones para } \\
\text { evitar y } \\
\text { resolver } \\
\text { accidentes de } \\
\text { forma que se } \\
\text { puedan evitar } \\
\text { daños } \\
\text { permanentes al } \\
\text { medio ambiente } \\
\text { y al personal de } \\
\text { la Planta. }\end{array}$ & $\begin{array}{l}\text { Prevención - } \\
\text { Operación/Operación/ } \\
\text { Mantenimiento }\end{array}$ & $\begin{array}{l}\text { Se deberá adquirir botiquines de } \\
\text { primeros auxilios para atender } \\
\text { accidentes leves que no necesiten } \\
\text { de asistencia médica urgente o } \\
\text { traslado del paciente hacia un } \\
\text { centro hospitalario. } \\
\text { Se dispondrá de extintores para } \\
\text { controlar conatos de incendio, en } \\
\text { todas la Áreas que supongan peligro } \\
\text { así como de posibles accidentes } \\
\text { como choques o volques de } \\
\text { maquinarias y vehículos. } \\
\text { Así mismo se adquirirán materiales } \\
\text { para control de derrames de } \\
\text { combustibles y sus derivados, estos } \\
\text { materiales pueden ser: aserrín, } \\
\text { guaipes, barreras absorbentes, kit de } \\
\text { derrames de hidrocarburos, entre } \\
\text { otros, los cuales se colocarán sobre } \\
\text { las áreas afectadas y una vez } \\
\text { controlados se dispondrán en } \\
\text { recipientes herméticos. }\end{array}$ & $\begin{array}{c}\text { Durante todo } \\
\text { el periodo de } \\
\text { operación de la } \\
\text { Planta }\end{array}$ & $\begin{array}{l}\text { Durante el } \\
\text { funcionamiento de } \\
\text { la Planta todos los } \\
\text { accidentes o } \\
\text { emergencias han } \\
\text { sido } \\
\text { contrarrestados en } \\
\text { forma eficiente. }\end{array}$ & $\begin{array}{c}\text { Ubicación en } \\
\text { lugares visibles } \\
\text { de las normas de } \\
\text { seguridad. } \\
\text { Ubicación y } \\
\text { colocación tanto } \\
\text { de extintores y } \\
\text { botiquines en } \\
\text { sectores de } \\
\text { peligro en la } \\
\text { Planta. }\end{array}$ & $2.080,00$ \\
\hline \multicolumn{8}{|c|}{ PROGRAMA DE PREVENCIÓN Y CONTROL DE IMPACTOS } \\
\hline $\begin{array}{l}\text { Reducción de } \\
\text { Generación de } \\
\text { Polvo }\end{array}$ & $\begin{array}{l}\text { Reducir el } \\
\text { impacto } \\
\text { generado por el } \\
\text { polvo hacia la } \\
\text { atmosfera } \\
\text { producido por } \\
\text { el manejo de } \\
\text { materiales y el } \\
\text { tráfico de } \\
\text { vehículos. }\end{array}$ & $\begin{array}{c}\text { Prevención / Mitigación - } \\
\text { Operación }\end{array}$ & $\begin{array}{l}\text { Se implementara un tanquero de } \\
\text { agua el cual deberá regar de modo } \\
\text { uniforme todas las superficies que } \\
\text { se encuentren expuestas, esto con la } \\
\text { finalidad de controlar la generación } \\
\text { de polvo. El transporte de material } \\
\text { pétreo desde y hacia la planta, se } \\
\text { realizará mediante el uso de } \\
\text { volquetes, los cuales deberán cubrir } \\
\text { completamente el material con } \\
\text { carpas, esto con la finalidad de } \\
\text { evitar derrames en las vías }\end{array}$ & $\begin{array}{l}\text { Durante las } \\
\text { fases de } \\
\text { Operación y } \\
\text { Cierre }\end{array}$ & $\begin{array}{c}\text { Se realizara el } \\
\text { riego } 3 \text { veces al } \\
\text { día de las } \\
\text { superficies que } \\
\text { generen polvo. } \\
\text { Se cubrirán los } \\
\text { sitios de } \\
\text { almacenamiento } \\
\text { de materiales }\end{array}$ & $\begin{array}{l}\text { Constatación } \\
\text { directa. } \\
\text { Registro } \\
\text { fotográfico. }\end{array}$ & 2100 \\
\hline
\end{tabular}




\begin{tabular}{|c|c|c|c|c|c|c|c|}
\hline $\begin{array}{l}\text { Control de } \\
\text { Ruido }\end{array}$ & $\begin{array}{l}\text { Controlar o } \\
\text { reducir el ruido } \\
\text { provocado por } \\
\text { la maquinaria } \\
\text { situada en la } \\
\text { Planta, a fin de } \\
\text { que no supere } \\
\text { los niveles } \\
\text { máximos } \\
\text { permitidos por } \\
\text { la normativa } \\
\text { ambiental } \\
\text { vigente. }\end{array}$ & $\begin{array}{c}\text { Prevención / Mitigación - } \\
\text { Operación }\end{array}$ & $\begin{array}{l}\text { Se deberá utilizar silenciadores en } \\
\text { los escapes de equipos, vehículos y } \\
\text { maquinaria utilizada en la Planta. } \\
\text { Se brindara mantenimiento } \\
\text { preventivo y correctivo a toda la } \\
\text { maquinaria y equipo para de esta } \\
\text { forma evitar la generación excesiva } \\
\text { de ruido. Se realizará monitoreos de } \\
\text { ruido a toda la maquinaria ubicada } \\
\text { en el lugar, esto con el fin de } \\
\text { verificar el cumplimiento de la } \\
\text { normativa ambiental. }\end{array}$ & $\begin{array}{l}\text { Durante las } \\
\text { fases de } \\
\text { Operación y } \\
\text { Cierre }\end{array}$ & $\begin{array}{l}\text { La maquinaria y } \\
\text { equipo generan } \\
\text { ruidos dentro de } \\
\text { los límites } \\
\text { permisibles. }\end{array}$ & $\begin{array}{c}\text { Registro } \\
\text { fotográfico } \\
\text { Registro de } \\
\text { mantenimiento } \\
\text { hacia la } \\
\text { maquinaria. } \\
\text { Reportes de } \\
\text { Monitoreos. } \\
\text { Constatación } \\
\text { directa. }\end{array}$ & $\begin{array}{c}19.800,0 \\
0\end{array}$ \\
\hline $\begin{array}{c}\text { Medidas } \\
\text { Ambientales } \\
\text { para el Área de } \\
\text { Mantenimiento }\end{array}$ & $\begin{array}{c}\text { Prevenir, } \\
\text { Mitigar y } \\
\text { Minimizar } \\
\text { riesgos e } \\
\text { impactos sobre } \\
\text { los diferentes } \\
\text { componentes } \\
\text { ambientales } \\
\text { ubicados } \\
\text { alrededor de la } \\
\text { Planta. }\end{array}$ & Prevención - Operación & $\begin{array}{l}\text { Toda la maquinaria además de } \\
\text { vehículos que se utilicen en la } \\
\text { Planta, deberán pasar por una } \\
\text { revisión técnica en la que se } \\
\text { garantice el buen estado mecánico y } \\
\text { operativo, para ello se deberá llevar } \\
\text { el control del mantenimiento } \\
\text { realizado. } \\
\text { Se deberá destinar un área de } \\
\text { mantenimiento esto para realizar las } \\
\text { reparaciones que necesiten tanto la } \\
\text { maquinaria como los vehículos. En } \\
\text { caso de fugas de combustibles, } \\
\text { aceites y grasas, se deberá adoptar } \\
\text { las medidas necesarias para evitar } \\
\text { derrames de combustibles. } \\
\text { Se dispondrá de un área para la } \\
\text { recarga de combustible, en caso de } \\
\text { ocurrir derrames fuera de esta área, } \\
\text { se deberá recoger los combustibles } \\
\text { con materiales absorbentes y retirar } \\
\text { el suelo contaminado. }\end{array}$ & $\begin{array}{l}\text { Durante las } \\
\text { fases de } \\
\text { Operación y } \\
\text { Cierre }\end{array}$ & $\begin{array}{c}\text { En el primer } \\
\text { trimestre de } \\
\text { funcionamiento de } \\
\text { la Planta se cuenta } \\
\text { con } 200 \mathrm{~m}^{2} \text { de área } \\
\text { para } \\
\text { mantenimiento y } \\
100 \mathrm{~m} 2 \text { para el } \\
\text { área de carga de } \\
\text { combustible, } \\
\text { debidamente } \\
\text { encementadas, al } \\
\text { contorno con } \\
\text { cunetas } \\
\text { impermeabilizadas } \\
\text { y una trampa de } \\
\text { grasas }\end{array}$ & $\begin{array}{l}\text { Registros } \\
\text { fotográficos. } \\
\text { Facturas de } \\
\text { compra de } \\
\text { materiales } \\
\text { Constatación } \\
\text { directa. }\end{array}$ & $4.600,00$ \\
\hline
\end{tabular}




\begin{tabular}{|c|c|c|c|c|c|c|c|}
\hline $\begin{array}{l}\text { Manejo de } \\
\text { Plantas de } \\
\text { Asfalto, } \\
\text { Trituradoras y } \\
\text { Cribas }\end{array}$ & $\begin{array}{l}\text { Mitigar los } \\
\text { impactos } \\
\text { ambientales } \\
\text { producto de la } \\
\text { operación de la } \\
\text { maquinaria } \\
\text { utilizada en la } \\
\text { Planta de } \\
\text { Asfalto, } \\
\text { Hormigón, } \\
\text { entre otras. }\end{array}$ & $\begin{array}{c}\text { Prevención / } \\
\text { Mitigación - Operación }\end{array}$ & $\begin{array}{c}\text { Todas las instalaciones deberán } \\
\text { contar con dispositivos } \\
\text { especialmente diseñados para evitar } \\
\text { la contaminación del ambiente, } \\
\text { como por ejemplo, derrames de } \\
\text { materias peligrosas, emisiones de } \\
\text { gases, ruidos y partículas } \\
\text { transportables por el viento. } \\
\text { Durante la operación de la Planta de } \\
\text { Asfalto, se prestará especial } \\
\text { atención al mantenimiento de los } \\
\text { equipos de control de los gases del } \\
\text { horno, por lo tanto se debe vigilar el } \\
\text { sistema de combustión, ya que éste } \\
\text { constituye un factor importante en } \\
\text { el control de emisiones en el horno. } \\
\text { Se deberá construir piscinas de } \\
\text { decantación para los residuos de } \\
\text { lavado de: camiones de transporte } \\
\text { de hormigón, sistemas de } \\
\text { abatimiento de polvo por medio de } \\
\text { agua, el funcionamiento correcto de } \\
\text { esta piscina permite evitar la } \\
\text { contaminación de las aguas } \\
\text { superficiales o subterráneas. } \\
\text { Alrededor de las zonas de } \\
\text { almacenamiento de combustible y/o } \\
\text { asfalto, se construirán cunetas } \\
\text { perimetrales con la finalidad de } \\
\text { evitar derrames y contaminaciones. }\end{array}$ & $\begin{array}{l}\text { Durante la fase } \\
\text { de Operación }\end{array}$ & $\begin{array}{c}\text { Tanto la Planta de } \\
\text { Asfalto como la de } \\
\text { Hormigón, y } \\
\text { demás } \\
\text { instalaciones, se } \\
\text { encuentran } \\
\text { cumpliendo con lo } \\
\text { establecido en el } \\
\text { Diseño del Plan de } \\
\text { Manejo Ambiental } \\
\text { por lo tanto causan } \\
\text { el menor impacto } \\
\text { ambiental posible. }\end{array}$ & $\begin{array}{c}\text { Registros } \\
\text { Fotográficos } \\
\text { Constatación } \\
\text { directa de la } \\
\text { infraestructura } \\
\text { Resultados de } \\
\text { monitoreos de } \\
\text { ruidos o gases. }\end{array}$ & $7.500,00$ \\
\hline $\begin{array}{l}\text { Almacenamiento } \\
\text { y Manejo de } \\
\text { Productos } \\
\text { Inflamables }\end{array}$ & $\begin{array}{c}\text { Almacenar y } \\
\text { manejar } \\
\text { adecuadamente } \\
\text { productos } \\
\text { inflamables }\end{array}$ & $\begin{array}{c}\text { Prevención - Operación/ } \\
\text { Mantenimiento }\end{array}$ & $\begin{array}{c}\text { Establecimiento de un área } \\
\text { específica para el almacenamiento } \\
\text { de productos inflamables. } \\
\text { Construcción de cunetas } \\
\text { perimetrales alrededor de las áreas } \\
\text { de tanques de asfalto. } \\
\text { Capacitación mediante la } \\
\text { impartición de charlas sobre el } \\
\text { manejo de productos inflamables, } \\
\text { prevención y control de accidentes }\end{array}$ & $\begin{array}{l}\text { Durante los } \\
\text { tres primeros } \\
\text { meses }\end{array}$ & $\begin{array}{l}\text { Construcción de } \\
\text { infraestructura } \\
\text { adecuada para el } \\
\text { almacenamiento } \\
\text { de productos } \\
\text { inflamables y sus } \\
\text { derivados. }\end{array}$ & $\begin{array}{c}\text { Registro } \\
\text { fotográfico } \\
\text { Constatación } \\
\text { directa de } \\
\text { infraestructura }\end{array}$ & $5.700,00$ \\
\hline
\end{tabular}




\begin{tabular}{|c|c|c|c|c|c|c|c|}
\hline & & & $\begin{array}{c}\text { e imprevistos, etc., al personal } \\
\text { encargado de esta área del proyecto. }\end{array}$ & & & & \\
\hline \multicolumn{8}{|c|}{ PROGRAMA DE CIERRE Y ABANDONO } \\
\hline $\begin{array}{c}\text { Plan de Cierre y } \\
\text { Abandono }\end{array}$ & $\begin{array}{c}\text { Plantear } \\
\text { procedimientos } \\
\text { adecuados para } \\
\text { el cierre y } \\
\text { posterior } \\
\text { rehabilitación } \\
\text { de las áreas } \\
\text { afectadas por el } \\
\text { Funcionamient } \\
\text { o de la Planta } \\
\text { de Producción } \\
\text { de Materiales } \\
\text { Pétreos, } \\
\text { Hormigón y } \\
\text { Asfalto. }\end{array}$ & $\begin{array}{c}\text { Prevención / Mitigación - } \\
\text { Cierre }\end{array}$ & $\begin{array}{l}\text { Al finalizar en su totalidad las } \\
\text { actividades, la Planta de Producción } \\
\text { de Materiales Pétreos, Hormigón y } \\
\text { Asfalto, se procederá con el cierre } \\
\text { de forma técnica de todas sus } \\
\text { instalaciones, especialmente se } \\
\text { pondrá énfasis las áreas de } \\
\text { mantenimiento, almacenamiento de } \\
\text { combustible, piscinas de } \\
\text { sedimentación, Área de } \\
\text { Almacenamiento de Desechos } \\
\text { Peligrosos, de las cuales se retirará } \\
\text { todo el material contaminante que } \\
\text { estén en estos sectores, los mismos } \\
\text { que finalmente serán transportados } \\
\text { a las escombreras o rellenos } \\
\text { sanitarios debidamente autorizados } \\
\text { por el GAD Municipal de } \\
\text { Gualaceo. } \\
\text { No se tendrá problema en las } \\
\text { instalaciones móviles de la Planta } \\
\text { ya que su retiro será inmediato y a } \\
\text { corto plazo. } \\
\text { En el caso de las instalaciones } \\
\text { construidas con estructuras } \\
\text { metálicas o de hormigón armado, se } \\
\text { deberá analizar su posible }\end{array}$ & $\begin{array}{c}\text { Al cierre de las } \\
\text { operaciones }\end{array}$ & $\begin{array}{c}\text { Al cierre del } \\
\text { proyecto se } \\
\text { contará con un } \\
\text { ambiente acorde al } \\
\text { entorno en el que } \\
\text { se encontraba el } \\
\text { lugar antes del } \\
\text { funcionamiento de } \\
\text { la Planta. }\end{array}$ & $\begin{array}{c}\text { Constatación } \\
\text { directa del retiro } \\
\text { de infraestructura } \\
\text { del lugar. } \\
\text { Registro } \\
\text { fotográfico }\end{array}$ & $6.000,00$ \\
\hline
\end{tabular}




\begin{tabular}{|c|c|c|c|c|c|c|c|}
\hline & & & $\begin{array}{c}\text { reutilización en futuras actividades } \\
\text { en el sector, en último de los casos } \\
\text { se considerara su demolición. } \\
\text { Finalmente ya retirada la } \\
\text { maquinaria y equipo, así como } \\
\text { instalaciones móviles, se procederá } \\
\text { con la limpieza y retiro de cualquier } \\
\text { tipo de escombros, desechos y } \\
\text { basura del sitio, tratando causar el } \\
\text { menor impacto posible en el área. } \\
\text { La fosa séptica construida para el } \\
\text { manejo de las aguas servidas será } \\
\text { descontaminada y sanitizada con el } \\
\text { uso de cal, para posteriormente ser } \\
\text { sellada. } \\
\text { Finalmente, se procederá a realizar } \\
\text { la revegetación del lugar con la } \\
\text { ayuda de especies nativas en } \\
\text { aquellos sectores que fueron } \\
\text { intervenidos. }\end{array}$ & & & & \\
\hline \multicolumn{8}{|c|}{ PROGRAMA DE MONITOREO Y SEGUIMIENTO AMBIENTAL } \\
\hline $\begin{array}{c}\text { Monitoreo del } \\
\text { Agua y Suelo }\end{array}$ & $\begin{array}{c}\text { Realizar el } \\
\text { monitoreo del } \\
\text { estado del agua } \\
\text { del rio Jadán } \\
\text { mismo que se } \\
\text { encuentra } \\
\text { adyacente al } \\
\text { área de la } \\
\text { Planta, así } \\
\text { como de los } \\
\text { suelos que } \\
\text { ocupa. }\end{array}$ & $\begin{array}{c}\text { Prevención / Mitigación - } \\
\text { Operación/ } \\
\text { Cierre }\end{array}$ & $\begin{array}{c}\text { Muestreo de agua: Se realizará un } \\
\text { monitoreo semestral de las aguas } \\
\text { del río. Las muestras serán tomadas } \\
\text { por personal técnico de un } \\
\text { laboratorio acreditado, cumpliendo } \\
\text { con la cadena de custodia, al } \\
\text { laboratorio para la realización de } \\
\text { los análisis correspondientes. Los } \\
\text { parámetros que se deberá realizar } \\
\text { como mínimo serán los siguientes: } \\
\text { DBO5, DQO, OD, Sólidos Totales } \\
\text { y Disueltos, Coliformes Totales y } \\
\text { Fecales, Aceites y Grasas, } \\
\text { Turbiedad, Nitratos y Nitritos. } \\
\text { Muestreo de Suelo: Se monitoreará } \\
\text { la calidad del suelo semestralmente, } \\
\text { para ello se tomarán tres muestras }\end{array}$ & $\begin{array}{l}\text { Dos veces al } \\
\text { año }\end{array}$ & $\begin{array}{l}\text { No han variado las } \\
\text { características } \\
\text { tanto del agua y } \\
\text { suelo. }\end{array}$ & $\begin{array}{c}\text { Resultados de los } \\
\text { análisis tanto del } \\
\text { agua como del } \\
\text { suelo } \\
\text { Facturas de pago } \\
\text { del laboratorio }\end{array}$ & $2.800,00$ \\
\hline
\end{tabular}




\begin{tabular}{|c|c|c|c|c|c|c|c|}
\hline & & & $\begin{array}{c}\text { de varios sectores, para de esta } \\
\text { forma establecer si los mismos } \\
\text { están siendo afectados en sus } \\
\text { características por la presencia de la } \\
\text { Planta. }\end{array}$ & & & & \\
\hline $\begin{array}{l}\text { Verificación del } \\
\text { Cumplimiento } \\
\text { del Diseño del } \\
\text { Plan de } \\
\text { Manejo } \\
\text { Ambiental }\end{array}$ & $\begin{array}{c}\text { Controlar y } \\
\text { mantener el } \\
\text { cumplimiento y } \\
\text { aplicación del } \\
\text { diseño del Plan } \\
\text { de Manejo } \\
\text { Ambiental. }\end{array}$ & $\begin{array}{c}\text { Prevención / Mitigación - } \\
\text { Operación/ } \\
\text { Cierre }\end{array}$ & $\begin{array}{c}\text { Para la verificación del } \\
\text { cumplimiento del Diseño del Plan } \\
\text { de Manejo Ambiental, se realizarán } \\
\text { dos tipos de monitoreos: } \\
\text { Monitoreo Interno. Este se lo } \\
\text { realizar internamente será realizado } \\
\text { por el personal técnico de la Planta. } \\
\text { Monitoreo Externo. Este lo } \\
\text { realizará el Ministerio del } \\
\text { Ambiente, ya que es el ente } \\
\text { regulador a nivel nacional. }\end{array}$ & $\begin{array}{c}\text { Se } \\
\text { implementara } \\
\text { desde el inicio } \\
\text { y durante toda } \\
\text { la Fase de } \\
\text { Funcionamient } \\
\text { o de la Planta. }\end{array}$ & $\begin{array}{l}\text { Por parte del } \\
\text { Técnico } \\
\text { Ambiental se han } \\
\text { realizado los } \\
\text { respectivos } \\
\text { Monitoreos para } \\
\text { verificar la calidad } \\
\text { ambiental. }\end{array}$ & $\begin{array}{l}\text { Informes de } \\
\text { Cumplimiento } \\
\text { del Diseño del } \\
\text { Plan de Manejo } \\
\text { Ambiental } \\
\text { Registro } \\
\text { Fotográfico }\end{array}$ & $\begin{array}{c}14.400,0 \\
0\end{array}$ \\
\hline & & & \multicolumn{3}{|l|}{ TOTAL } & \multicolumn{2}{|c|}{$\begin{array}{c}94.085,00 \\
\text { USD }\end{array}$} \\
\hline
\end{tabular}




\section{Conclusion}

La identificación de los impactos ambientales permitió desarrollar programas los cuales estuvieron enfocados a minimizarlos, al mismo tiempo se pretende dar un manejo adecuado y proteger los recursos naturales como son el suelo, agua, flora y fauna que se encuentran en la Planta.

El mayor impacto ambiental generado por el funcionamiento de la Planta es la contaminación del ambiente por partículas de polvo y el incremento de los niveles de ruido los cuales afectan a los trabajadores.

La cobertura vegetal como la fauna existente en el lugar ha sido la mayor perjudicada por el funcionamiento de la planta, eso se puede constatar a simple vista ya que existe una escasa cobertura vegetal por ende se puede evidenciar un mínima presencia de fauna.

Para el diseño del presente plan de manejo ambiental se ha considerado las necesidades tanto de los trabajadores como de la población cercana al lugar.

Cabe recalcar que algunos de los programas planteados en el presente diseño de plan de manejo ambiental se han cumplido en el transcurso del tiempo, ya que la Planta se encuentra actualmente en funcionamiento.

El área donde está ubicada actualmente la Planta es un área totalmente intervenida por lo tanto las afectaciones al ambiente producto del funcionamiento temporal son de baja magnitud y pueden ser manejadas con la aplicación de medidas preventivas.

\section{References:}

1. Cañadas, L. El mapa bioclimático y ecológico del Ecuador (1986). Quito. Ecuador.

2. Estadística ARCOM. (2015). Informe Estadístico de Mineria. Retrieved from https://view.officeapps.live.com/op/view.aspx?src=http://www.contro Iminero.gob.ec/wpcontent/uploads/downloads/2016/11/ESTADISTICA_MINERA_201 5_noviembre20161.xls

3. García, A. (2013). Manual sobre manejo de planta de hormigón. Retrieved from http://es.martinezgarcia/wiki/Plantadehormigonón

4. González, M. (2007). Modelo de Gestión Administrativo Financieropara La Empresa Comercializadora de Materiales de Construcción y Ferreteria. Instituto de Altos Estudios Nacionales. Retrieved from http://repositorio.iaen.edu.ec/bitstream/24000/61/1/IAEN-0182007.pdf

5. Páez, J. (1991). Introducción a los métodos de evaluación de impactos ambientales: recomendaciones para los gobiernos 
seccionales de Ecuador. Fundación Natura.

6. Ramírez, M. (2008). Sostenibilidad de la Explotación De Materiales De Construcción En el Velle DE Albura. Universidad Nacional de Colombia. $\quad$ Retrieved from http://www.bdigital.unal.edu.co/950/1/43207166_2009.pdf

7. TULAS. (2013). Texto Unificado de Legislación Secundaria del Ministerio del Ambiente del Ecuador. 